\title{
Product innovations of key economic importance for the steel industry ${ }^{\star}$
}

\author{
Jean-Pierre Birat ${ }^{*}$ \\ IF Steelman, Semécourt, France
}

Received: 4 May 2017 / Accepted: 8 January 2018

\begin{abstract}
Steel and materials in general entertain a special connection with time and therefore with innovation. Indeed, steel has been around for more than 4 millennia and is still innovating, which demonstrates both a status of socio-economic invariance and a cumulative innovation process, which deeply differs from the status of the "high-tech" consumer products, which are considered today as highly innovative. This is a complex situation, which is best described by telling various narratives from the standpoint of history, innovation management, sustainability, economy and business, with both long and short times perspectives. The Historian's perspective insists on slow time, especially as regards innovation, in which steel took part. Steel and steel production technology have thus accompanied society in its long journey through time since the Neolithic, Roman and Celtic times, the Middle Ages, Modern Times and Industrial Revolutions. Today, the technological episteme seems to be frozen in a stasis that has been rolling out global steelmills across the world and most recently in China. The present technological paradigm was built under the pull of the social and economic drivers which have led to the geopolitical world as it is today. Innovation today, continues, but not visibly at the level of process engineering, but regarding metallurgy and material science, thus exploring the deep connection of steels with specific and always changing applications. Regarding process engineering, however, the on-going economic transitions, i.e. the energy, ecology and digitization transitions, may awaken Sleeping Beauty's castle and relaunch a new series of paradigm shifts in making steel. Low-carbon technologies are being explored to meet the Climate Change challenge, which may rekindle the sustainability innovation driver. And a reexamination of the scale at which steel is made might possibly stem from Additive Manufacturing, although this is still a weak signal as far as steel is concerned.
\end{abstract}

Keywords: steel / steel industry / process engineering / low-carbon technologies / additive manufacturing / innovation / technology paradigm shift

\section{Introduction}

Steel plays a special role in the economy in as far as it has been a sustainable invariant of the various technological epistemes, that have followed up after one another over extended historical times. This continues to be true today and it will remain so for long times to come. While the European Commission has been conceptualizing this under the name of Key Enabling Technologies (KETs) ${ }^{1}$, of which

\footnotetext{
$\star$ Text of a presentation given to the OECD Steel Committee, Paris, 1 December 2015

* email: jean-pierre.birat@ifsteelman.eu

${ }^{1}$ Micro and nanoelectronics, nanotechnology, industrial biotechnology, advanced materials, photonics, advanced manufacturing and processing technologies. Steel is deeply related to advanced materials and to advanced processing technologies.
}

advanced materials are part with steel one of their particular avatars [1], the importance of steel extends beyond the relatively short-term time extension of EC policy strategy, reaching deep into the past down to the Neolithic period and far into an indefinite future, and beyond the economic realm, as steel is indeed a basic element around which society has organized its needs. Steel is thus a socio-economic invariant. Steel is not completely unique as it shares its particular features with materials in general or material resources including water, with a physical quantity like energy and with societal concepts like mobility, sheltering, food and health ${ }^{2}$. What is interesting is that steel is part of a relatively short list of deeply essential elements of our social structure.

\footnotetext{
${ }^{2}$ This is related, to some extent, to the Societal Challenges defined by the EC.
} 
Talking about innovation is one way of analyzing the particular role of steel, but there are many others. They depend on the viewpoint from which the analysis is carried out. The concept of story telling is useful to encompass the variety of stories that are told by various experts and interest groups. We have therefore chosen here to speak of steel through different narratives and to select those that are related to innovation and change, as this is the primary interest of the meeting today. What is interesting with narratives is that each one expresses a specific worldview, culture and even philosophical angle. Because, even if narratives are not necessarily coherent and might even be contradictory, all of them are true.

Economic and business narratives about steel abound, especially in the meetings of the Steel Committee of the OECD [2]. The first one is the "steel intensity narrative", which connects GDP per capita with steel intensity per capita [3]. The second one is the "steel cyclicality narrative" and it is deeply related to the third one, the "overcapacity narratives", narratives in the plural actually, as one school of thought assumes that the present overcapacity is structural, while another posits that it is temporary and will vanish when the world eventually escapes from the 2008 crisis [3]. A fourth economic narrative is related to globalization, i.e. the advent of global steel.

The narratives of relevance for the present discussion are the "historical narrative", "the innovation driver narrative", "the metallurgical narrative", "the materials science and nanotechnology narrative", "the value chain narrative", "the sustainability narrative" and "the 3rd industrial revolution narrative". They will be analyzed in the various sections of this paper.

\section{The historical narrative or the construction of the concept of innovation}

Iron is one of the most prevalent elements in the universe, forged in the core of stars and then aggregated in the telluric planets like Earth. It is therefore natural that mankind empirically understood how to make use of it and benefit from its outstanding properties.

The detailed history of how the process and product technologies of iron and steel were developed lies outside of the scope of the present paper [4]. It is, however, part of the continuing history of innovation in steel, told by prehistorians (the first smelting of iron dates back to the 3rd millennium B.C.), historians and anthropologists rather than by innovation experts, engineers or economists, as would be the case for describing today's state of the art.

To make a long story short, iron and steel were initially produced in the solid state and this lasted for several thousand years (bloomery and finery). The technology had a very low productivity compared to that of today (a $10^{-7}$ ratio, at the very least), but it matched the quantitative needs of society for iron and steel during this period [5]. Modern steel production was ushered in by conquering the liquid state, i.e. first by producing liquid pig iron in the Middle Ages in Europe (the bloomery evolving into the Flußofen and then the Blast Furnace, based on charcoal and then on coke from earth coal) and then liquid steel in the 19th century (crucible steel, puddled iron, Sir Henry Bessemer's converter (1855) [6], the Martin family's Open Hearth Furnace [7], the Electric Arc Furnace (EAF) of Héroult). This showed an acceleration of progress in the technology of making iron and steel, or rather in the productivity of the trade. It went along with the ability to increase processing temperatures and eventually to understand heat transfer technology empirically and later scientifically, like in thermodynamics.

The introduction of new technology related to steel production is a complex storyline, which cannot simply be explained by continuous progress in engineering ${ }^{3}$. While archeologists long took it for granted that the introduction of new technologies led to demographic and then economic growth and improved the well-being of people, thus making new technology a prerequisite to progress, today's anthropologists [8] and sociologists [9] have a more subtle and interesting viewpoint.

First they would discard the concept of progress altogether and they would point out that technology only appeared after society had developed the related concepts and therefore the needs for what it would lead to: as if technology was always potentially there, but would only be tapped when a strong "societal demand" would materialize. This questions concepts like invention, inventors, patents and management of innovation as none of these seem to have been in the driver's seat.

The acceleration of history and correspondingly of technology, which has taken place since the time of the industrial revolution and the beginning of entrepreneurship, brought forth inventors identified by name (Darby, Bessemer, Siemens, Martin, Héroult, etc.) and worked out a concept of innovation: as if inventors had been invented at that time, taking precedence over craftsmen who had worked anonymously before.

Note also that the major accelerations in iron and steel production, at the end the 18th and then in the second half of the 20th century have been related to major changes in transport technology: the railroad and its steam-engine trains on the one hand and the automobile on the other, complete with their infrastructures. Steel is the offspring of transport and thus is deeply related to its value chain, to use a modern expression.

\footnotetext{
${ }^{3}$ The formulation of physics and chemistry, of thermodynamics and of metallurgy brought concision of formulation to the ability to become quantitative and predictive. It has become possible to optimize the production of electricity, but it is now the scale effect makes gigantic steel mills make possible. The high productivity has become accessible because of the all-through liquid ironmaking and steelmaking. This can be achieved because of the complexity sophistication of the present engineering episteme. It is in no way obvious that today's steelmaking is more sophisticated than the bloomery and finery-based technology of the Middle Ages or even of the "rougher" tools that the Celts used: it is aimed at different needs of society. In this sense, the notion of progress should not be taken for granted: the blacksmiths of 30 generations ago were just as talented and skilled as modern-day operators in an elite!
} 


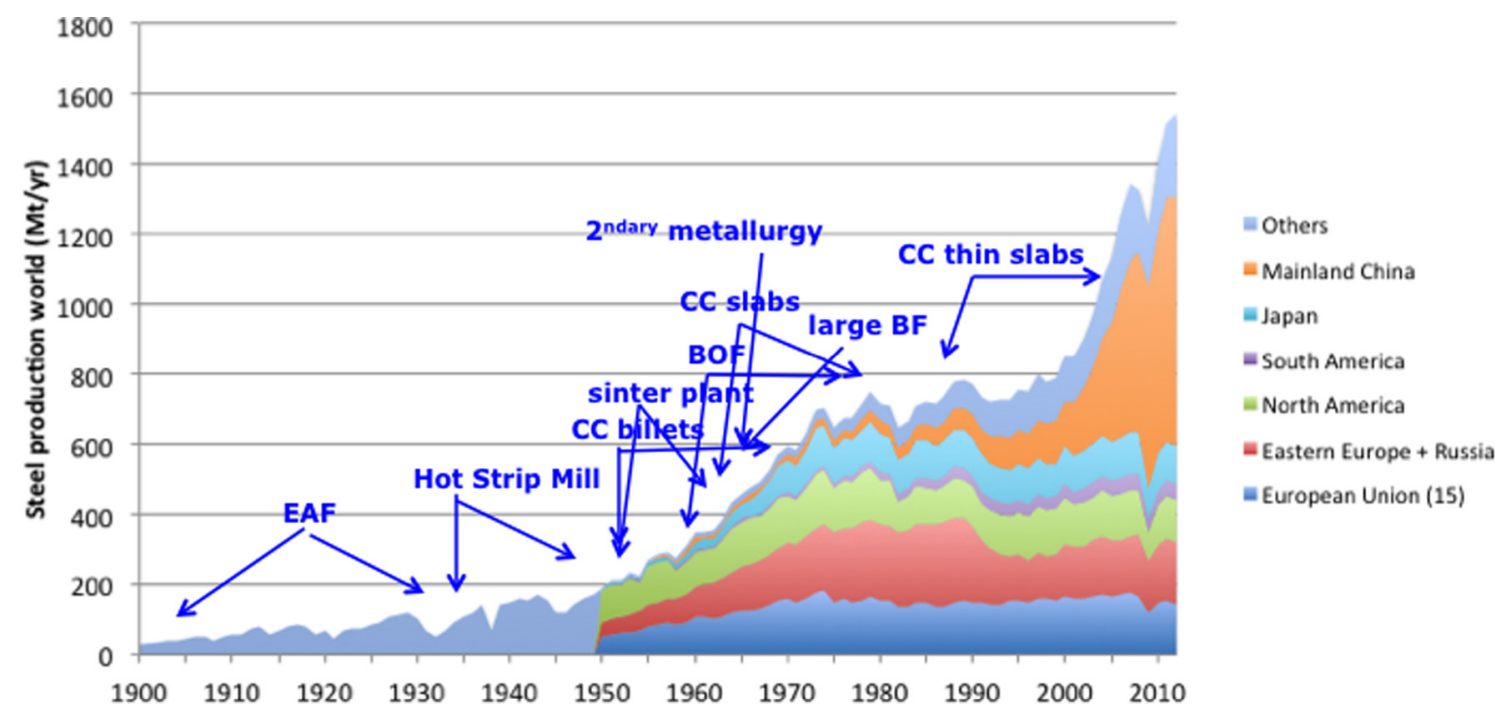

Fig. 1. Time evolution in the introduction of new process technologies in the 20th century.

Some more detailed analysis of the origin of the present technological episteme universally used in modern steel mills is necessary in order to speak of today's steel sector.

The modern steel mill was based on the need to adapt to the exponential growth of the economy that took place after WWII and thus to the deployment of mass production in the steel sector. This is shown schematically in Figure 1, where the invention and the initial mass deployment of a new technology is indicated by two successive arrows: thus the EAF was mostly deployed for the production of special steels in the first half of the 20th century, but then it was introduced in flat product mini-mills in the 60s $\left(\right.$ Italy $\left.^{4}\right)$ and then the 80s (US, most of the world), with a growth in reactor size and production capacity.

The Hot Strip Mill (HSM) kindled the transformation of the whole process route. While it had been invented in the US prior to WWII, it was deployed in Europe immediately afterwards, often as part of the Marshall plan, and in Japan.

Then all the tools in the process route changed and adapted to match the throughput of the HSM, from the sinter plants, "giant" blast furnaces, continuous casting, the BOF and its avatars (bottom blowing, combined blowing). Some elements of the route were added to respond to other innovation drivers (e.g. secondary metallurgy responding to the need for steel quality and cleanliness). The outcome was a production route coherent in terms of the capacity of each production step and operating seamlessly, continuously at the level of each plant (continuous reactors like the sinter plant, the blast furnace, continuous casting, continuous annealing; semi-continuous reactors operating under a tight schedule like the tap-to-tap time in the steel shop, e.g. the BOF, the EAF, the HSM) and sometimes with direct connection between plants (e.g. hot charging of slabs). The capability of each process step was stretched and production scheduling optimized. This transformation

\footnotetext{
$\overline{{ }^{4} \text { Not shown on the figure. }}$
}

extended over 30 years and occupied most of the second half of the 20th century. Today's new steel mills built in emerging countries use this technological paradigm as it was perfected in Europe, the US and Japan, 20 years or more ago.

As far as steel production routes are concerned, robustness and stability are in place for an indefinite length of time, as long as steel production will continue to increase [3]. Only major qualitative changes in the economy and in society's values might modify this statu quo.

\section{The innovation drivers narrative}

The driving forces that led to the present technological episteme of the steel industry can be understood from the evolution of steel production over the last 110 years shown in Figure 2. At the end of World War II, steel production geared into higher speed to match the needs for broad strip that the burgeoning and soon exploding car manufacturing sector required. Steel mills went into a mass-production mode and, as explained in the previous section, adapted process technology by building hot strip mills, capable of producing several million tons per unit and then worked to develop a coherent series of upstream and downstream tools, which would channel through this high level of production: oxygen steelmaking and continuous casting were "invented", perfected and generalized, blast furnaces became larger and fully reliable.

The second wind came in response to the need to correct excesses linked to mass production by focusing on quality: the effort was concentrated on the steel shop, with the invention and generalization of secondary-ladle metallurgy and an increased sophistication in continuous casting (production of clean steels).

Then came the difficult times of cost cutting, which brought down the manpower in the steel sector by increasing productivity by a factor $2-3$, at the cost of severe social hardship. 


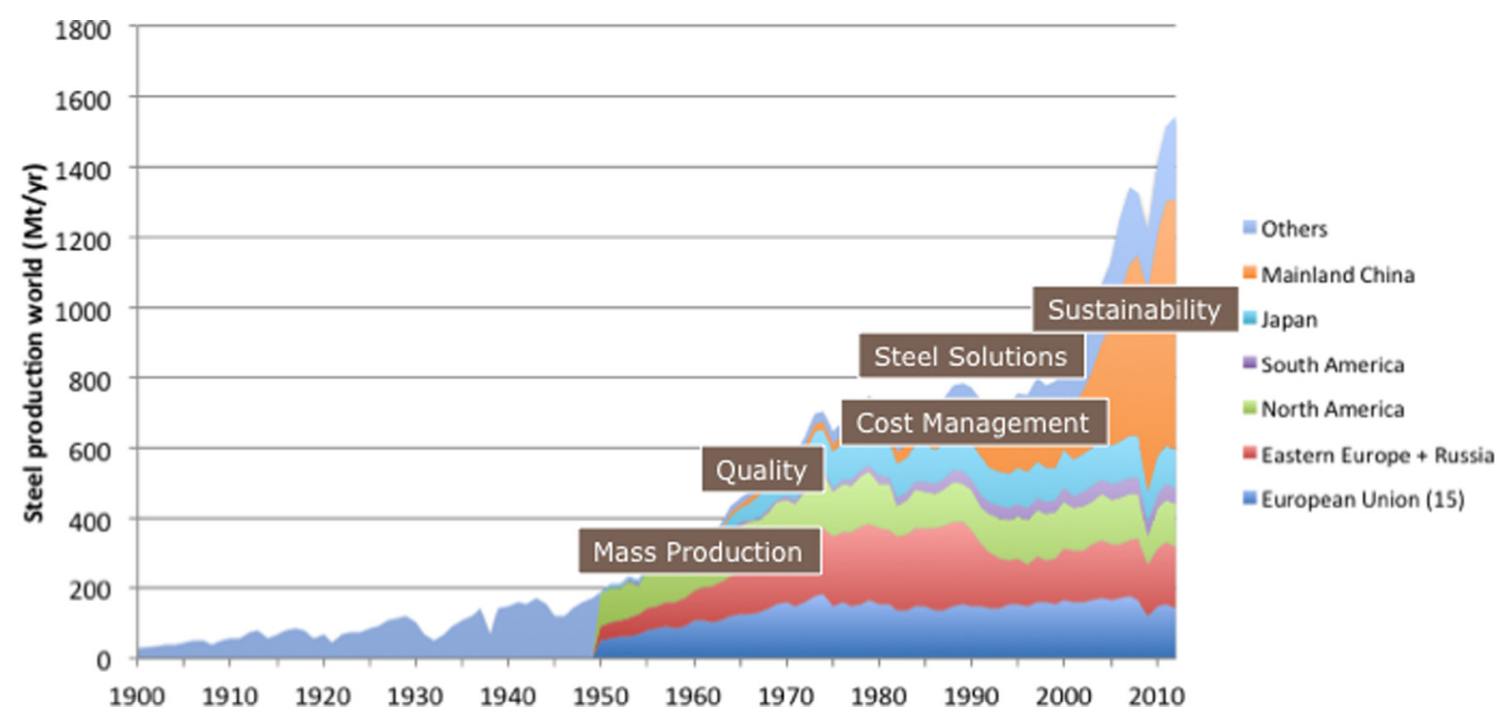

Fig. 2. innovation paradigms driving steel process technology since the middle of the 20th century.

The renaissance that followed was associated with the understanding that steel was not simply a metallurgical object but was offering a service to customers and thus was to be sold as tailor-made steel solutions for a booming scope of market needs - what was called customer engineering.

Finally, the sector understood that clean steels had to be produced in a clean manner, i.e. sustainably: this has been the most recent driver of innovation, of a different nature form the previous one, as environmental constraints were an externality in the market economy and legislation had to jump start the process, until it was understood that clean steelmaking is an economically sound way of producing clean steels. This might turn out to be the third wind of steel mill process technology for a long time to come, for example because of the need to reduce $\mathrm{CO}_{2}$ emissions drastically.

\section{The metallurgical narrative}

What is the connection between steel use and steel production, i.e. between product and process innovation?

They evolved in parallel, starting from iron (prereduced iron in modern terminology), pig iron (hot metal) and going through all variants of steel, natural steel, Damascus steel, puddling iron (la tour Eiffel), Bessemer steel, etc.

Modern steels became available with the advent of liquid steel production [10]. Beyond carbon steels, were invented stainless steels, tool steels and high speed steels (with carbide forming additions), high-manganese steels (Hatfield, 1882), silicon electrical steels, Maraging steels (dispersion strengthened), bearing steels and engineering low-alloy steels, TRIP (Transformation Induced Plasticity) steels of the stainless steel family, TRIP steels of the carbon steel family, TWIP (TWinning Induced Plasticity) steels, micro-alloyed carbon steels (HSLA), Advanced High Strength steels, etc.

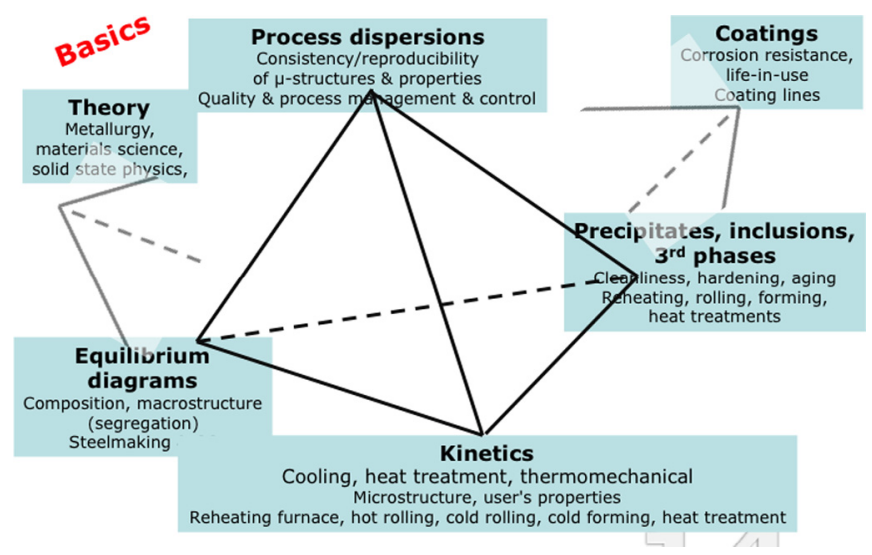

Fig. 3. schematics of steel metallurgy issues.

The metallurgical narrative about steel can be organized on the four apexes of a tetrahedron (Fig. 3):

- steel is essentially a simple iron-carbon alloy, thus born of thermodynamics equilibrium as exemplified by phase diagrams and high-temperatures, involving liquid processing at equilibrium: equilibrium between hot metal and the coke bed in the blast furnace, between hot metal and $\mathrm{BF}$ slag, steel and slag in the converter or the EAF or the ladle, steel and atmosphere - oxygen, nitrogen and hydrogen -, equilibrium at the dendrite tips during solidification, etc. The composition of steel and therefore its initial equilibrium macrostructure, including segregation, are driven by these equilibriums;

- when steels solidifies, kinetics take precedence and the interesting world of non-equilibrium phases opens up the infinite variety of metallurgical structures, by giving metallurgy an extra-control parameter, actually several, related to heating, maintaining at a constant temperature and then cooling more or less quickly; all of these can moreover take place under stress. These are called heat treatment, quenching or thermo-mechanical treatments. 
The outcome is the microstructure of the commercial steels, sometimes quite different from the equilibrium structure of the phase diagrams. That microstructure determines properties in use.

Thus the high temperature physical chemistry of ironmaking, of steelmaking and of solidification takes place at thermodynamic equilibrium, while the solid state metallurgy of steels is non-equilibrium metallurgy, driven by kinetics and various distances to equilibrium: two domains responding to two different ways of thinking and two very different metallurgical cultures. The former is responsible for potentially high efficiency in terms of energy and raw material use, while the latter gives access to the complexity of steel grades:

- steel is more complex than the simple $\mathrm{Fe}-\mathrm{C}$ diagram, because of the long litany of other elements, most of them in small concentrations in the iron matrix (trace elements, residuals, micro-alloying elements) or present outside of the metal matrix as third phases, i.e. nonmetallic inclusions (NMI) and precipitates. NMIs determine cleanliness, while precipitates add a level of complexity to solid-state metallurgy by introducing specific interactions with dislocations and with the nucleation of new allotropic phases at lower temperatures;

- the fourth apex represents an important feature of steel production, i.e. the fact that a steel shop cannot be run as a manufacturing plant in the automotive sector, because the control on the hundreds of steelmaking parameters exhibit natural dispersions that add up to a kind of intrinsic uncertainty. Full computer control of production is presently out of reach, although a sophisticated level of Integrated Intelligent Manufacturing (I2M) has been introduced in the steel mill;

- two extra apexes were added in an effort to avoid oversimplification: basic metallurgy as a theoretical discipline, which lies at the basis of many new developments in steel metallurgy, and coating technology, an essential theme to make it possible to use steel for long lives and avoid rusting.

Steel is not simply handled by the steel sector and its value-chain, as defined in its narrow economic sense, but also by other economic sectors.

At an industrial level, powder metallurgy [11], foundry or die casting [12] and tube \& pipe production are not usually considered as part of the steel sector ${ }^{5}$. They produce both steel and pig iron besides non-ferrous metals. Their toolbox of process technologies is sometimes quite different from the steel sector's as they explore physical domains that are not those of a steel mill ${ }^{6}$ : for example,

\footnotetext{
${ }^{5}$ They are thus not included in statistics in terms of steel production or turnover, as published by worldsteel, Eurofer or the OECD, for example.

${ }^{6}$ The evolution of steel production in the 20th century has been focused on standardizing a few sets of technologies and thus in shutting off wide areas of physical parameters, which should be kept in mind for exhaustivity's sake and for keeping all future options of the sector open.
}

while classical foundry carries out solidification in the same parameter brackets as steel production, specialized techniques stray away from them ${ }^{7}$, such as single crystal production of turbine blades, precision molding, producing near-net-shape or net-shape moldings or injection molding. While welded pipes are produced from steel coils, some tubes are produced directly from the melt, such as seamless tubes, by combined centrifugal continuous casting and Mannesmann tube-piercing and rolling, or as centrifugally cast tubes of large dimensions, a technique which is akin to foundry.

There are more confidential areas, connected to specialized technologies, which exist in the netherworld between very small industrial activity and research:

- Mechanical Alloying, but also mechanical solid reduction, uses fragmentation of powders down to nanometric dimensions, to produce materials out of thermodynamic equilibrium. It is actually now a technique used extensively to produce nanostructured materials;

- Thixocasting, Rheocasting and Thixoforming handle solid and liquid mixtures in the solidification interval. The challenge of controlling such a narrow temperature gap is the reason for its confidential development. The advantage is high precision in the geometry of casts, as solidification shrinkage is reduced. These technologies are mostly used in non-ferrous applications (aluminum, magnesium) but work is continuing on stainless and carbon steels;

- spray casting, developed by professor Springer and now Sandvik-Osprey of South Wales, projects supercooled liquid droplets on a cooled substrate. A low material yield is its main challenge, but it is used to make some special niche copper alloys, like prematerial for low temperature $\mathrm{Nb}_{3} \mathrm{Sn}$ superconductors (CuSn). Applications to steel seem to have been shelved for the time being;

- rapid solidification produces amorphous metal, foils, wires or powders, by quenching the liquid into a viscous state. The amorphous phase can only be obtained with products of small thickness or diameter. Applications in the case of steel or iron are small confidential niches (safety tags in shops);

- production of metal foams was a hot subject in the 1990s and, indeed, foams of most common metals were produced in the laboratory. The material inches its way into commercial applications, for example aluminum foam in the bottom of the door in a Citroën Aircross concept car [13]. Steel foam production is concentrated on stainless steels. The challenge is to produce a material with reproducible and uniform geometry and properties and the only present method for making regular, nonstochastic foams is a foundry technology of CTIF. Its advantages are a low density (5-25\% of the pure bulk metal) and a high resistance to bending. Cf. Figure 4.

Finally, at the boundaries of steel metallurgy lie, on the high-carbon side, pig-iron and its many variants, like lamellar graphite or spheroidized graphite and, on the

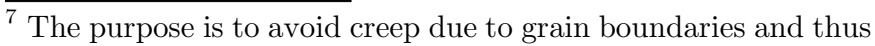
to improve high-temperature mechanical properties significantly.
} 


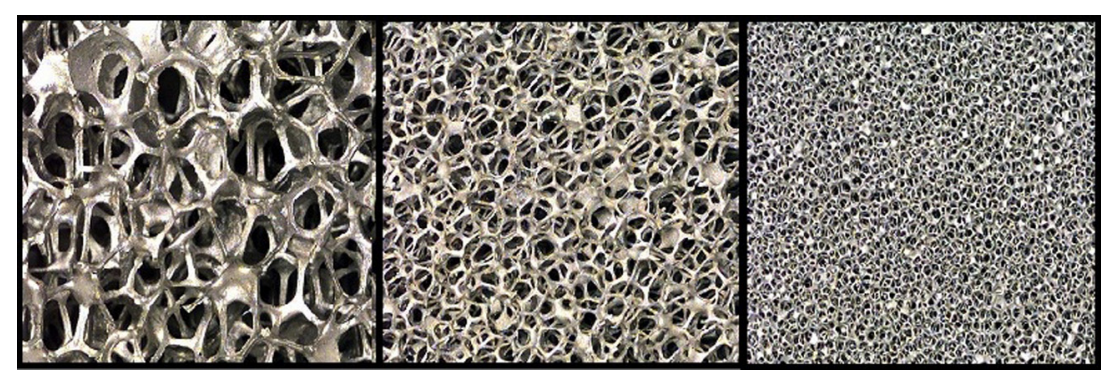

Fig. 4. Porous foams made by FeCrAlY: stainless steel, nickel, nickel alloys, copper, brass, steel, titanium castings - 10-30 \& 60 ppi [15].

high-nickel side, superalloys. Pure iron, at the boundary of extra purity, is not really a steel variant - although some very pure iron is known as "Armco iron" [14] - but rather a material standard used for applications in physics; it is produced by electrolysis or chemical reactions in the laboratory.

A number of new metallurgical concepts, old or recent, have made some inroad in steel technology, although at the level of technological forecasting (prospective) and as weak signals rather than confirmed trends yet. Superplasticity and its use in the steel sector was one of them but it never turned into commercial reality, although there has been renewed interest at Stanford and the Livermore Laboratory in connection with ultra-high carbon steels, which take their roots in Damascus steel [16]. More recent ones are architectured materials [17,18], nanomaterials strongly connected to steel and additive manufacturing - familiarly known as 3-D printing.

Discussing innovation in steel metallurgy is complex, because steel is a cumulative technology, which has been piling up experience, knowledge and practices for historical periods of time [19]. This is completely different from the idea of innovation that marketing has popularized in its product maturity S-curve (birth, growth and death of a commercial product). This is also different from discussing overarching technologies, which evolve in discrete steps, or industrial revolutions ${ }^{8}$ - like the 1st one in the Neolithic, the 2 nd one in the 18th and 19th century and the 3rd one about to come, if the rational of Jeremy Rifkin is to be believed [20].

The process of making steel has evolved very significantly since the bloomery of the Hittites. It has now been frozen into a dichotomic technical scheme, the integrated steel mill and the electric mill. The component technologies (blast furnace, on the one hand, electric arc furnace on the other, etc.) have stopped changing significantly and are using patterns perfected 20 or more years ago. This is bound to continue for a while, although some new process innovation paradigm might redefine the context and rekindle process innovation.

\footnotetext{
${ }_{8}$ The concept of industrial revolution is not necessarily taken for granted by science and technology historians and the numbering of the revolutions is not uniform across authors either. The 1st industrial revolution is often identified as related to the utilization of steam and the 2 nd one of electricity.
}

Now, what is the innovation status of steels, steel metallurgy and steel utilization? [21]

Steel metallurgy and grades have been developed to a very large extent ${ }^{9}$ over the last 100 years. Most of the basic options have probably been identified and explored fairly extensively.

At the basic level of physical metallurgy, of mechanical metallurgy or of chemical metallurgy, it would seem that $l a$ messe soit dite, although experts have a long list of issues still needing to be clarified [22] (like understanding the structure at the core of a dislocation) - and they will indeed clarify them in the natural course of academic research.

At the detailed level of each steel grade, the basic understanding of the metallurgy involved can also be improved, especially since new grades, which are actually deviations from existing compositions, come up regularly because of new application needs (e.g. the 3rd generation nuclear power plants or more simply the $10 \mathrm{MW}$ wind turbines) or of tension regarding resources ( $\mathrm{Co}, \mathrm{V}, \mathrm{Ni}$, etc.). The understanding needs also to be practical, operational, i.e. be implementable on a production line, with the level of safety and regularity of production imposed by high output, extended service life and global production. Defining a new grade that scientists can already describe in principle takes months or years. Identifying a robust way of producing them commercially in a steel mill and deploying the practice to the many different steel mills of a steel producer across the world is also a major contemporary challenge, that uses up large $\mathrm{R} \& \mathrm{D}$ resources in steel companies. Imagining seemingly small changes in process technology, like switching from slab to thin slab casting, raises technical issues that will also keep scores of R\&D engineers busy for months, as each steel grade, already commercially available today, has to be reengineered to fit the new process route.

The tension towards new grades is driven by the detailed needs of industry, society and customers, today. This is described in the "value-chain narrative" and each reader will position the effort involved on his own scale of innovation. The demand for this kind of innovation will not slacken any time soon, as long as industry will continue

\footnotetext{
9 The complexity of metallurgical system can be compared to that of a biological system. In an analogy with transfinite numbers $(\aleph)$, metallurgy is high on that scale, although maybe somewhat below life sciences.
} 
addressing new challenging issues - for example in connection with the energy transition, the low-carbon economy or the ecological transition.

Radically new metallurgical concepts can also be imagined as explained in the next section. Moreover, radical changes in the economic and industrial context can also induce radical changes in the steel offer. Historically, major changes were actually always achieved by a dialectic dialog between process and product metallurgy and this will continue in the future.

Note also that progress in this area as in many others in society, should not be taken for granted. For example, highend steels for the aircraft \& aerospace industries have been oriented towards fool-proof, fail-safe production routes, based on sophisticated steelmaking followed by remelting and slow solidification, sometimes several times (ESR, VAR), and on strict and rigorous procedures guaranteed by standards. This has frozen progress rather efficiently, as powerful drivers for change (quality - achieved, and cost "don't care too much!") had been removed - and this has ensured the safety of air travellers also rather satisfactorily. A similar criticism could be addressed to the construction sector, where Eurocodes [23,24] have frozen the definition of material grades, by making it difficult to obtain permission for evolutions. There are thus limits to the use of strict standards and therefore potential for change in the area!

\section{The materials science and nanotechnology narrative}

The name of Materials Science was coined in the 1960s, when it was intuitively understood that the methods and concepts of metallurgy could be used for a larger class of materials than metals. This was coincidental with the development of completely new materials (semiconductors, polymers, superconductors, superfluids, liquid crystals, Bose-Einstein condensates, etc.), and with the ability to deal theoretically with unusual ones (e.g. soft materials like powders (matière molle), bio-sourced materials). When metallurgy changed its name to materials science, it enrolled ceramics, an alreadydeveloped discipline. As shown in Figure 5, the methodological approach, however, is the same as metallurgy's.

In the Material Science narrative, steel is simply one element of one class of materials, metals, which are actually unusually ordered and therefore "simple". Thinking of steel in this context opens up new horizons and offers opportunities, which might have been more difficult to identify in the narrower context of metallurgy.

Note that solid-state physics has also provided intellectual and scientific fuel to metals, by clarifying their relationship with quantum mechanics and explaining their physical properties (electronic bands).

Material science has been regularly proposing new concepts, like rapid solidification leading to amorphous materials or micro-grained structures, thermo-mechanical treatments and controlled rolling, unidirectional solidification, single crystal growth (turbine blades), mechanical alloying, eutectic composites, composites, metal-matrix composites, quasi-crystals, ODS materials, fullerenes,

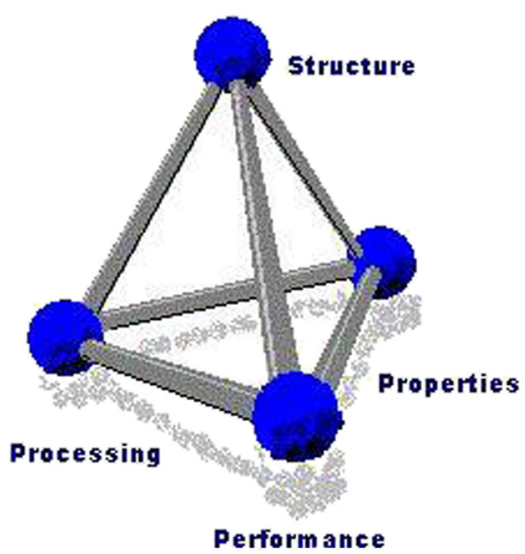

Fig. 5. the "material science tetrahedron".

graphene, diamond coatings, architectured materials, association of materials through various joining technologies, etc. This has been an effort to reconnect the discipline with the marketing concept of new products and to provide academics with more publication opportunities.

Note, however, that material scientists have indulged in the rhetoric of promises (ROP) [25], whenever a new material concept came up: fantastic applications were imagined, very early in the development of a new material and without any serious basis as it was assumed that it would replace existing materials quickly and thoroughly. This never happened and most of the new concepts have either disappeared, or, more often, carved off a niche of applications where their peculiar features offer original services. Today, ROP is alive and well in connection with graphene, for example, and with the next-in-line concept, stanene.

Material science is now almost passé and the new fashionable concept is nanotechnology. While it can be argued that "nanotech" stems from metallurgy and materials science, nanotechnology has outgrown this intellectual crib and focuses on technologies and materials which are designed to show order at the nano-scale, i.e. the scale of atoms, and thus to follow physical laws which are different from macroscopic physics, with sometimes even a quantum mechanical dimension.

\section{The value chain narrative}

In the $1980 \mathrm{~s}$, the steel sector became broadly aware of the need to customize steels beyond the metallurgical concept of grade in order to match the needs of particular applications. This was a transposition in the steel business of the concept of product-service theorized in marketing. Various expressions have been used to name this trend, like customer engineering or steel solutions and recently valuechain awareness.

A steel user today does not simply pick up a steel grade from a catalog any longer: he works with the producer to develop a grade, complete with primary (in the steel mill) and secondary (in the customer production site) processing steps. Each part calls on a specific new material, at least as far as rather sophisticated applications are concerned 


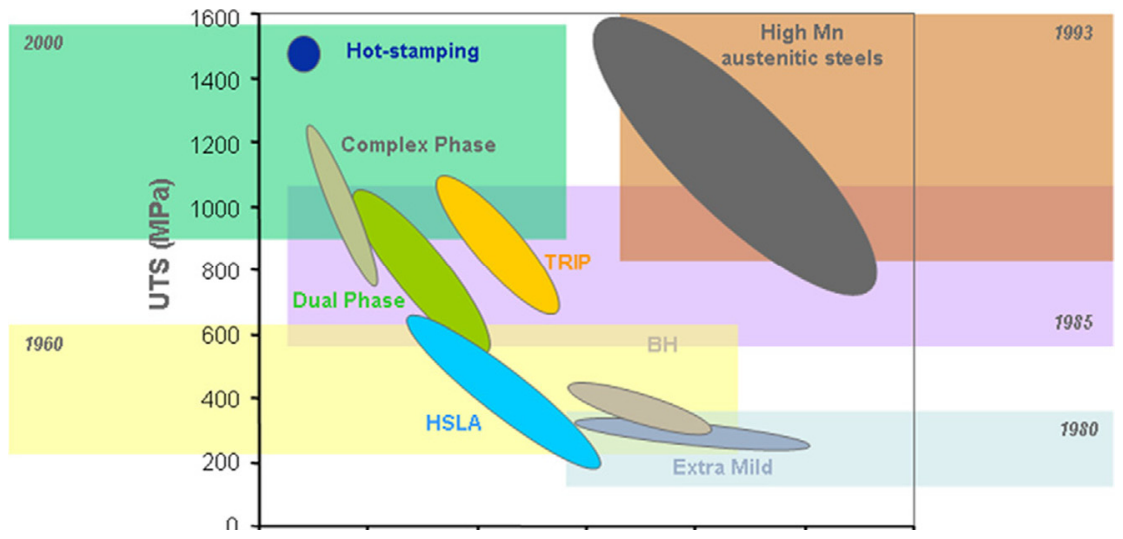

Fig. 6. The familiarly called "banana curve" for car applications, with indication of when the grades were developed to full MRL.

Table 1. Evolution of emission targets for various indicators and output streams projected from 2010 to $2050^{16}$.

\begin{tabular}{lllllll}
\hline Substances & 2000 & 2010 & 2020 & 2030 & 2040 & 2050 \\
\hline GHC & $0 \%$ & $10 \%$ & $20 \%$ & $30 \%$ & $40 \%$ & $50 \%$ \\
VOC & $0 \%$ & $24 \%$ & $49 \%$ & $60 \%$ & $70 \%$ & $81 \%$ \\
$\mathrm{SO}_{x}$ & $0 \%$ & $20 \%$ & $75 \%$ & $77 \%$ & $62 \%$ & $79 \%$ \\
$\mathrm{NH}_{3}$ & $0 \%$ & $0 \%$ & $27 \%$ & $44 \%$ & $62 \%$ & $79 \%$ \\
$\mathrm{PM}$ & $0 \%$ & $0 \%$ & $50 \%$ & $50 \%$ & $50 \%$ & $50 \%$ \\
$\mathrm{NO}_{x}$ & $0 \%$ & $26 \%$ & $53 \%$ & $64 \%$ & $74 \%$ & $85 \%$ \\
others & $0 \%$ & $10 \%$ & $20 \%$ & $30 \%$ & $40 \%$ & $50 \%$ \\
\hline
\end{tabular}

(cars).The steel producer delivers a set of microstructures and properties, plus instructions for using the steel, from a holistic modeling of the complete value chain.

Many steel producers have reorganized their research laboratories and sometimes their production mills to match specific markets. They also have resident engineers sitting at automotive OEM design departments to help them create new models, part by part.

This value-chain approach is fairly original to the steel sector ${ }^{10}$. It started in the subsector of engineering steels and has developed to flat carbon steels. The car industry has served as a trendsetter in both cases (cf. Fig. 6). This has also caused steel to steer away from commodification.

This close connection with customers has dynamized the steel sector, by enrolling steel producers and steel users together in the innovation drive.

Sectors pulling innovation in steel are the car industry (flat steel of high strength and high ductility, cf. Figure 6, engineering steels, electrical steels, sandwich steel, advances in materials processing like hot stamping of metal parts and in joining technologies), in spite of the much publicized competition of lighter materials, which is more often than not based on improper assumptions and on a disregard to

\footnotetext{
${ }^{10}$ The European Commission is presently putting much emphasis on "the value-chain approach" and pushing it to material producers in general.
}

the Life Cycle Assessment (LCA) dimension, the construction sector, which accounts at world level for half of steel consumption, with concepts like negative or zero-energy buildings, consumer and industrial packaging, and the energy sector where the generation of renewable energies is more steel intensive than fossil fuel-based or nuclear power generation.

There are other sectors though, where innovation may be more cosmetic, and therefore where proposing new products from the steel producer's side is the driver of innovation rather than responding to institutionalized demand from large, concentrated industrial sectors. This is the case in the construction business or in the technology of chemical or biotechnological reactors, where creativity has been proactive, proposing many kinds of surface functions, in line with what all materials have been doing: grafting of enzymes on the surface to avoid bacterial infestation [26], optimization of tribologic properties, adsorption of corrosion inhibitors - if possible originating from green chemistry, deposition (PVD, plasma, etc.) of coatings like nitrides or diamond, deposition of a photocatalyzer in order to generate a self-cleaning surface or a reactor to destroy organic pollutants $\left(\mathrm{TiO}_{2}\right)$, surface passivation, sol-gel deposits [27], polymer-steel composites, solar cells deposited on steel sheets or beams [28,29], green walls (murs végétalisés), etc. Nanotechnology and biomimetics are often quoted in connection with these ideas as well as high-tech applications such as electrodes for fuel cells [30]. 
The contrary concept should not be forgotten, i.e. steels that do not require surface customization like weathering steels (the customized surface is actually self-generated), or steels used as coating on other materials.

\section{The sustainability narrative and environmental metallurgy}

Environmental and sustainability issues are "externalities" in metallurgy today, but are gaining importance in decision making (like material selection), due to regulations, plain facts (e.g. accepting that climate change is real) and the understanding that they constitute opportunities and not threats to the steel sector [31].

The Sustainability issues relevant to the present narrative are many and they would constitute the chapters of a textbook on environmental metallurgy [31]:

- corrosion of steel is the only environmental issue that is not an externality but is part of "classical" metallurgy;

- the matter of Resources and Raw Materials is important in today's world, when the "Earth overshoot day" is announced now in the middle of the Summer ${ }^{11}$ [32] and tensions are obvious in raw material and energy resource markets, even when scarcity is not an immediate issue, as is the case with iron ore and coal, the main primary raw materials that steel calls upon. Physical (geological) limits or economical limits (mining capacity) create high volatility in prices $^{12}$. The solution proposed by the European Commission to release the resource geopolitical tension felt by Europe is to accelerate the entry into play of the circular economy. Steel, however, has been engaged in the circular economy literally for centuries and is today the "most recycled" material in the world (85\%), but, due to its long residence time in the economy (35 years), the direct production of steel by the EAF route today is only $28.2 \%^{13}$ in the world, $39.8 \%$ in Europe and $39.4 \%$ in the US [33]. Thus, the advent of a full recycling economy for iron and steel will not take place before the end of the century. The circular economy also deals with waste management and industrial ecology synergies with other economic activities and the steel sector is objectively active and performing well in these areas as well.The motto of Julian Allwood, "use twice less resources for twice as long" shows also a path towards more resource efficiency [34];

- energy and particularly exergy consumptions are high in the steel sector, which is labeled as one of the energyintensive industries (EII) - sometimes also called process industries (SPIRE).The amount of potential energy saving is fairly low, 8-15\%, depending on the performance level of a steel mill, because energy use has been strictly optimized, as it represents a large part (20-25\%) of operating cost in a steel mill [35]. Harvesting some of

\footnotetext{
${ }^{11}$ E.g. on 13 August 2015.

12 At the time of writing, prices of iron ore (55.32 US\$/t) and oil (42.93 US\$/barrel) are at a record low.

${ }^{13}$ This is close to the recycled content of present steel production, although some scrap (10\%) is used by the BOF route as well, and the EAF is charged with some pig iron (10\%).
}

the fatal heat is under way. A major challenge for the steel sector will be to adapt to the energy transition, which is under way at least in Europe;

- emissions to air $\left(\mathrm{CO}_{2}\right.$ \& GHG emissions, dust, VOC, etc.), to soil and water are under severe constraints due to strict regulations in most parts of the world. However, these constraints are likely to increase significantly until 2050 , because of the "globalization of air and water pollution" and the increase in urbanization. Climate Change and its constraints on GHG emissions are particularly serious and the targets for 2050 are higher than announced in the table, up to 80-95\% today in the EU. Because of the high energy efficiency of the steel sector, cutting GHG emissions is not simple and breakthrough technologies will have to be deployed, a process started with the ULCOS program [36] but still incomplete. Note the long-term possibility of making steel by electrolysis: this would break the golden rule of all-through liquid phase production as electroreduction in the ULCOWIN process takes place at $120^{\circ} \mathrm{C}$ [37]. This would in turn make it possible for steel to play a significant part in the design of smart electricity grids, necessary for incorporating high fractions of intermittent renewable electricity generation by implementing demand-side load management [38]. Note also that ULCOS solutions, except for electrolysis, incorporate CCS in order to reach a sufficient level of $\mathrm{CO}_{2}$ mitigation;

- steel has a Social and a Sustainability Value (cf. SAM conferences [39]), which has an upside (contribution to GNP, employment and society well-being through the anthropospheric services that steel performs beyond its market value) compared to the downside of the previous elements listed under sustainability issues. Adequate tools have to be used, starting from LCA, Material Flow Analysis (MFA) and Sustainability Assessment of Technology (SAT) and extending towards new metrics describing the sustainability value of steel;

Material design and material selection in product design are based on the premise, usually taken for granted, that an optimization should be carried out to use the best possible material, offering the best possible properties to make a particular product. This is based on an economic optimization, explicit or implicit, and this is not necessarily compatible with a sustainability assessment: critical raw materials have become critical because designers have called on them beyond naturally available resources. A new paradigm, based on slightly less optimized materials, might have to be adopted: frugal design. This is not new, as copper, for example, is used in most electrical circuits, even though silver would be a "better" engineering choice!

\section{The 3rd industrial revolution narrative}

The future of steel is not in doubt as all estimates for the mid-century project a doubling of production, more or less. However, beyond this global statement, many questions remain open. What is the future of steel in Europe, for example? Can countries like Japan and Korea maintain an excess of steel production compared to their domestic 
needs? Are the present steel mills frozen forever in their process technology? How quickly and how deeply are new steels or new steel solutions being proposed?

The answers hinge on the kind of futures that lies ahead. On the one hand, there is a technology-optimistic vision that states that indefinite progress lies ahead of us. On the other hand, pessimistic visionaries stress the finiteness of Earth, the unsustainable footprint of present societal paradigms or the dangers of climate change.

Optimistic people follow, for example, the projections of Jeremy Rifkin [20], who sees so many new innovative concepts turning into practical technologies in an upcoming future, that he speaks of a 3rd industrial revolution and thus of a new golden age to follow up on the present dim economic context in Western countries. He also explains that this goes along with a complete overhaul of the economy based on what he calls zero-marginal cost products and services [40]. The technologies that should trip the world into this new era are: renewable and decentralized energy (with energy storage), new IT (cloud, Internet of Things (IoT), "new" robotics, artificial intelligence and deep learning), Big Data, additive manufacturing, nanotechnology, advanced materials, autonomous vehicles and advances in biology (genomics for example $)^{14}[41]$. Not everyone buys this approach in its entirety, although politicians and organizations like the European Commission are mostly sympathetic to it. The rhetoric of promises (ROP) serves many masters! Now, some of this will no doubt happen, especially in terms of new technologies (digitalization, IoT, renewable energy, etc.) even if the outcome may not be as brilliant in terms of economic growth and job creation as Rifkin makes it sound.

The less optimistic people are divided into truly pessimistic ones, who foresee no less than doom, and more empirical and practical ones, who see the energy and the ecology transitions, complete with low-carbon technologies $^{15}$, as a way to overcome the present societal and political problems. This may be a more realistic way to picture an evolution that may, or may not, turn out to be a major paradigm shift in the technological episteme.

This raises many challenges to the steel sector, which need to be tackled head on $[42,43]$. Of particular interest is the possibility for some steel production to move away from the mass production scheme that is the norm today, towards more local and fractionized production, at the level of small production units or even under the direct control of the final customer, that additive manufacturing promises (ROP) and may eventually, in some extent, deliver for metals and steel in particular. In terms of foresight vocabulary, this is a major uncertainty.

\section{Conclusions}

Iron and steel have been deeply embedded in society and in its technological epistemes since the Neolithic. Like most

\footnotetext{
${ }^{14}$ To integrate this list, a concept has to have the word "new" attached to it!

${ }^{15}$ This includes Carbon Capture and Storage (CCS).
}

materials, but, probably more intensively, steel has been a kind of invariant, a Cumulative Key Technology, which has been continuously providing services to society and to the anthroposphere beyond the price paid by steel users in analogy with Biodiversity and Ecosystemic Services.

For example, steel is the backbone of the energy system, in its present and future avatars.

More generally, materials provide barriers between the ecosphere and the anthroposphere and, in this latter case, between technological artifacts and the living and working spaces of people: steel is particularly able to provide the strong gradients of properties (strength, temperature, pressure, chemical potential) which this implies.

Note that this has been made possible by an excursion to high temperatures, where steel is produced under thermodynamic equilibrium, and then by quenching the metal into the present room temperature and normal pressure environment (or into an industrial environment), where it is clearly out of equilibrium.

The kind of ecosystemic services provided by steel have been called anthropospheric or eco-techno-systemic services. This is part of a new understanding of the role of steel and materials in society and the advent of a new way to look at metallurgy called environmental and societal metallurgy [44].

Steel plays this role by offering a string of steel grades and steel applications, which have been changing over historical times, even if it is basically the same material transcending time.

More recently, due to the explosive growth of the world economy at the end of WWII and its reigniting at the transition of centuries by the emergence of BRICS countries, steel has adapted its volume of production, production technologies, quality, grade \& solution offer accordingly. This has led to the global concept of the giant modern steel mills, which reached a level of perfection 20 years ago and are not evolving any more. The steel offer is more dynamic than process technology, as the demand from some steel markets is continuously challenging steel producers.

Large and smaller steel companies deliver steel in a global context. The competition is lively, driven by cost and quality and by a dedicated offer of steel solutions, aimed at the specific needs of particular customers. On another hand, there is also an unusual level of professional cooperation among steel producers through a network of regular international conferences, of pre-competitive research programs (RFCS in Europe, AISI in the US, NEDO in Japan), of cooperation agreements between competitors on specific topics (e.g. the alliance between NSC \& ArcelorMittal) or of joint ventures in cold rolling plants (in the US, India, Turkey and China in the case of ArcelorMittal).

Even if competitors in the Steel sector offer similar steels in terms of service and properties, they are all subtly different.

The story of steel and of steel product development has been told here in several different manners, calling on different narratives. What is essential is that all of them are true $[45,46]$, which reflects the complexity of steel production and use and of their relationship to the anthroposphere. 


\section{References}

1. Key Enabling Technologies, European Commission, 6/2015 on line version, available at http://ec.europa.eu/growth/ industry/key-enabling-technologies/index_en.htm

2. 79th Session of the steel committee, OECD,Paris, France, 2015

3. J-P. Birat, Steel industry: culture and futures, 49-70, Selection of lectures in honor of CAI Kaike, progress in clean steelmaking and continuous casting, Metallurgical Industry Press, Beijing, China, 2015, 434p.

4. J.-P. Birat, Alternative ways of making steel: retrospective and prospective, La Revue de Métallurgie-CIT, 937-955 (2004)

5. P. Brun, P. Ruby, L'âge du Fer en France. Premières villes, premiers états celtiques, Inrap - La Découverte, 2008

6. J.-P. Birat, The relevance of Sir Bessemer's ideas to the steel industry in the 21st century, Ironmaking \& Steelmaking, La Revue de Métallurgie-CIT, juillet-août, 587-598 (2004)

7. J.-P. Birat, R. Nicolle, Invention du procédé d'élaboration de l'acier sur sole, dans Recueil des Commémorations nationales 2015, 224-225, Paris, Éditions du patrimoine/Ministère de la Culture et de la Communication - Archives de France (mission aux Commémorations nationales), 2014, 334 p.

8. A Testard, Avant l'histoire, l'évolution des sociétés de Lascaux à Carnac, Bibliothèque des Sciences Humaines, nrf, éditions Galiimard, 2012, 549 p.

9. B. latour, Pasteur: guerre et paix des microbes, Paris, La Découverte, 2001

10. M. PELOU, Les aciers de fabrication française, Éditions Sciences et Industrie, 1956

11. PM Industry Roadmap, 2012, available at https://www. mpif.org/IntroPM/2012_Industry_Roadmap.pdf

12. The European Foundry Association, available at http:// www.caef.org

13. Available at http://www.ctif.com/de-la-mousse-metalliquecastfoam-sur-le-concept-car-aircross-de-citroen/

14. Available at http://www.aksteel.co.uk/1-products/0-ingotiron/

15. Available at http://www.selee.com/Selee_Corporation Metal_Foam_2.php

16. J. Wadsworth, O.D. Sherby, The history of ultrahigh carbon steels, The Metallurgical Society, 1997, available at http:// www.osti.gov/scitech/servlets/purl/611842/

17. Y. Brechet, Architectured Materials: an innovative pathway for materials development, Matériaux 2014, Montpellier, 2014

18. D. Embury, O. Bouaziz, Steel-Based Composites: Driving Forces and Classifications, Annu. Rev. Mater. Res. 40, 213-241 (2010)

19. N. Ohashi, Innovation and technical development in the Japanese steel industry, Columbia University Academic Commons, 1992, available at http://hdl.handle.net/10022/AC:P:91

20. J. Rifkin, The third industrial revolution, how lateral power is transforming energy, the economy and the world

21. Managing Innovation in the Steel Industry, Steel research Hub, 2014, available at http://steelresearchhub.uow.edu. $\mathrm{au} / \mathrm{managing-innovation/index.html}$

22. A. Pineau, Y. Quéré, La métallurgie, science et ingénierie, Académie des Sciences et des technologies, 147, 17 (2011)

23. Available at http://www.eurocodes.fr/en/index.html

24. The EN Eurocodes, the Eurocodes building the future website, available at http://eurocodes.jrc.ec.europa.eu/
25. La science du cerveau n'existe pas. A propos du Human Brain Project. Interview de F. Panese par M.-L. Théodule. La Recherche 493, 90 (2014)

26. A. Caro, V. Humblot, M.J.G Minier, M. Salmain, C. Compere, C-M. Pradier, Fonctionnalisation de surfaces d'acier inoxydable par des enzymes en vue d'inhiber l'adhésion de bactéries et la formation de biofilms en eau de mer, Matériaux \& Techniques 94, 455 (2006) DOI: 10.1051/mattech:2007020

27. J.-P. Bonino, E. Xuereb, J. Esteban, F. Ansart, Les revêtements sol-gel pour l'anticorrosion, Matériaux \& Techniques 99, 41 (2011) DOI: 10.1051/mattech/2011012

28. Available at http://www.arcelormittalinfrance.com/news/ 2013/sept/12-09-2013.aspx?sc_lang=fr-FR

29. Available at http://www.enerzine.com/1/12270+tata-steeldeveloppe-des-poutrelles-solaires.+ html

30. Available at https://www.ulg.ac.be/cms/c_99126/fr/arce lormittal-et-l-ulg-inventer-le-futur-de-l-acier

31. J.-P. Birat, Environmental metallurgy: continuity or new discipline?, Steel Research International, Special Issue: Science and Technology of Steelmaking 85, 1240 (2014) DOI: $10.1002 / \operatorname{srin} .201300279$

32. Global footprint network, Jour de dépassement, available at http://www.footprintnetwork.org/fr/index.php/GFN/page/ earth_overshoot_day/

33. World steel in figures, worldsteel association, 2014

34. J. Allwood, SAM-9, Luxembourg, 2015

35. Steel production - energy efficiency working group Final report, B. de Lamberterie editor, ESTEP-EUROFER report, January 2014, available on ftp://ftp.cordis.europa.eu/pub/ estep/docs/wg7-final-report.pdf accessed on 1 August 2015

36. J.P. Birat, J. Borlée, H. Lavelaine, D. Sert, P. Négro, K. Meijer, J. van der Stel, P. Sikstrom, ULCOS PROGRAM: AN UPDATE IN 2012, 4th International Conference on Process Development in Iron and Steelmaking, Luleå, Sweden, 2012

37. H.L. de Maubeuge, A. Allanore, J.P. Birat, Iron electrowinning a process route for ultra low $\mathrm{CO}_{2}$ in steelmaking, Keynote Lecture at 61st Annual meeting of the International Society of electrochemistry, 2010

38. J.-P. Birat, H. Lavelaine, Steel production \& smart electricity grids, available at http://cordis.europa.eu/estep/docs/steelproduction-and-smart-electricity-grids-website2.pdf

39. Available at www.sovamat.org

40. J. Rifkin, The zero marginal cost society, The internet of things, the collaborative commons, and the eclipse of capitalism, Palgrave MacMillan, 2014, 356p.

41. Disruptive technologies, Advances that will transform life, business, and the global economy, Mc Kinsey Global Economics, 2013

42. J.-P. Birat, Will the energy and ecology transitions change the game for an energy-intensive industry like steel?, AIST Italy Steel Forum, Dalmine, Italy, 2015

43. J.-P. Birat, H. Lavelaine, The eco-techno-systemic services that steel plays in the energy system, SCANMET 2016

44. J.-P. Birat, Sustainable Materials Science, Environmental Metallurgy, EDP Sciences, 2018, in press

45. J E. Wideman, All stories are true, in "All Stories Are True: The Stories of John Edgar Wideman", 1994

46. K. Birat, All Stories are True: prophecy, history and story in the cattle killing, Callaloo, Volume 22, Number 3, Summer 1999

Cite this article as: Jean-Pierre Birat, Product innovations of key economic importance for the steel industry, Metall. Res. Technol. 115, 420 (2018) 